\title{
Virologic suppression in response to antiretroviral therapy despite extensive resistance within HIV-1 reverse transcriptase after the first virologic failure
}

\author{
Marta Iglis Oliveira ${ }^{1} \mathbb{D}$, Valter Romão de Souza Junior ${ }^{3 *}$ (D) Claudia Fernanda de Lacerda Vidal ${ }^{2}$
} and Paulo Sérgio Ramos de Araújo ${ }^{1,2}$

\begin{abstract}
Background: Incomplete virologic suppression results in mutations associated with resistance and is a major obstacle to disease control. We analyzed the genotypic profiles of HIV-1 patients at the time of the first virologic failure and the response to a salvage regimen after 48 weeks.

Methods: This work was a cross-sectional, retrospective, analytical study based on data collected from medical records and genotyping tests between 2006 and 2016. The sample consisted of data on individuals living with HIV $(\mathrm{PLWH})$ from three major reference centers.

Results: A total of 184 patients were included in the data analysis. Viral subtype B was the most common (81.3\%) as well as M184 V/I (85.3\%) and K103 codon mutations (65.8\%). Forty-eight weeks after switching to a salvage regimen, $67.3 \%$ of patients achieved an undetectable viral load.

Discussion: The number of mutations associated with nucleos(t)ide reverse transcriptase inhibitors (NRTI(t)s) did not affect virologic suppression (9.3\% for zero NRTI(t)-associated mutations vs $48.6 \%$ for $1-2 \mathrm{NRTI}(\mathrm{t})$-associated mutations vs $42.1 \%$ for $\geq 3 \mathrm{NRTI}(\mathrm{t})$-associated mutations, $p=0.179$ ). An ARV time (the beginning of the first ARV regimen up to genotyping) of $>36$ months was a protective factor for detectable viral load (PR $=0.60,95 \% \mathrm{Cl}$ $=0.39-0.92, p=0.020)$ and a risk factor for developing $\geq 3 \mathrm{NRTI}(\mathrm{t})$-associated mutations ( $\mathrm{PR}=2.43,95 \% \mathrm{Cl}$ $1.38-4.28, p=0.002)$.
\end{abstract}

Conclusions: We found that extensive resistance to NRTI(t)s at the time of the first virologic failure did not impact virologic suppression at 48 weeks after switching to a second-line therapy based on NRTI(t)s plus protease inhibitors.

Keywords: HIV-1 drug resistance, Genetic diversity, Subtypes, Antiretroviral therapy

\section{Background}

Approximately 21 million people are living with HIV (PLHIV) and receiving antiretroviral therapy [1], which is responsible for a significant decrease in their morbidity and mortality as well as in the risk of transmission $[2,3]$. However, the importance of this therapy to global health has been threatened by an increased prevalence of resistance to antiretrovirals

\footnotetext{
* Correspondence: jr_walter@hotmail.co.uk

${ }^{3}$ Faculdade de Medicina do Recife, Universidade Federal de Pernambuco, Av. Prof. Moraes Rego, 1235, Recife, Pernambuco, Brazil

Full list of author information is available at the end of the article
}

(ARVs), which has increased from 11 to $29 \%$ since 2001 [4]. Of the individuals under ARV treatment, $20 \%$ will have to switch ARVs due to virologic failure $[5,6]$. Thus, drug resistance is a real obstacle to viral suppression and disease control [1].

In Brazil, approximately $60 \%$ of PLHIV receive ARVs [7] through a program by the Brazilian Ministry of Health. From 2004 to 2017, the first-line therapy in the country was based on regimens involving efavirenz (EFV), a non-nucleoside reverse transcriptase inhibitor (NNRTI). In 2013, tenofovir (TDF) became the preferred nucleos $(\mathrm{t})$ ide reverse transcriptase

(c) The Author(s). 2018 Open Access This article is distributed under the terms of the Creative Commons Attribution 4.0 International License (http://creativecommons.org/licenses/by/4.0/), which permits unrestricted use, distribution, and reproduction in any medium, provided you give appropriate credit to the original author(s) and the source, provide a link to the Creative Commons license, and indicate if changes were made. The Creative Commons Public Domain Dedication waiver (http://creativecommons.org/publicdomain/zero/1.0/) applies to the data made available in this article, unless otherwise stated. 
inhibitor $(\operatorname{NRTI}(t))$, and it was given in a single dose combined with lamivudine (3TC) and EFV [8]. In 2017, dolutegravir (DTG), an integrase inhibitor that was administered with TDF/3TC, became the first-line therapy [9].

Genotypic and immunovirologic data from patients following the first virologic failure are scarce in Brazil, and they are limited to certain regions of the country. A recent study from the city of São Paulo ${ }^{10}$ on patients who failed first-line therapy between 2013 and 2015 found a higher prevalence of the M184 V/I mutation (74.3\%) and K103 codon (56.7\%), similar to that found in other Brazilian states [11]. Among the 205 subjects who started the second-line therapy with $\operatorname{NRTI}(t) s$ combined with protease inhibitor/ritonavir (PI/r), 76.6\% experienced virologic suppression $(<200$ copies $/ \mathrm{ml})$, despite the extensive resistance of the virus to $\operatorname{NRTI}(t) s$ [10].

Low- and middle-income countries in sub-Saharan Africa, where $70 \%$ of PLHIV live [1], access 2 NRTI(t) + NNRTI as a first-line therapy [12]. This regimen has a low genetic barrier and easily results in cross-resistance. Thus, the sensitivity of NRTI(t)s may be compromised by multiple mutations that arise during the first virologic failure. In addition, $\operatorname{NRTI}(\mathrm{t}) \mathrm{s}$ have recognized risks of toxic effects. These factors are concerning and have led to the decision to retain this drug class as a second-line therapy, and they have motivated the development of randomized clinical trials to evaluate the efficacy of the salvage regimen with $\operatorname{NRTI}(t)$ s plus $\mathrm{PI} / \mathrm{r}$.

Mutations are associated with high reduced susceptibility or virologic response to relevant NRTIs. Mutations reduce NRTI susceptibility or virologic response, which contributes to reducing susceptibility in combination with other NRTI-resistant mutations. The impact of mutations associated with NRTI(t)s during the second-line regimen was evaluated through the SECOND-LINE, EARNEST and SELECT studies [13-15] and they were recently reevaluated in a meta-analysis [20], which showed the success of salvage regimens based on NRTI(t)s combined with PI/r. In this study, we analyzed the genotypic profile of HIV-1 in patients during the first virologic failure and the predictors of virologic success 48 weeks after switching to a salvage regimen.

\section{Methods}

This work was a cross-sectional, retrospective, multicenter study evaluating genotypic resistance tests of PLHIV during the first virologic failure in the city of Recife, the capital of the state of Pernambuco, an important medical center in Northeast Brazil. The patients were enrolled in three large centers specializing in the care of PLHIV. We reviewed tests that were performed from January 2006 to December 2016 and included patients over 18 years of age who had used ARVs for more than six months and presented two consecutive viral load measurements, with an interval of at least 30 days, and values greater than 1000 copies $/ \mathrm{ml}$. Individuals who underwent ARV switching due to virologic failure without genotyping tests, those who used ARVs before receiving the first-line therapy, those showing an absence of mutations associated with resistance in genotyping, and those with insufficient data were excluded.

The immunovirologic and genotypic data and the history of ARV use were collected from genotyping tests, medical charts and through the Laboratory Test Control System (Sistema de Controle de Exames Laboratoriais SISCEL- online platform). To identify the mutations associated with resistance, the ViroSeqTM HIV-1 Genotyping System kit (Celera Diagnostics, Alameda, CA, USA) was used from 2006 to 2008 and the TRUGENE System (Siemens, Munich, Germany) was used from 2009 to 2016 by the laboratories that served the National Genotyping Network (Rede Nacional de Genotipagem - Renageno). The viral load (VL) was measured until July 2013 using the Versant HIV-1 RNA 3.0 assay (bDNA, Siemens, USA); real-time qPCR was used after this date (Abbott Laboratories, USA). The CD4 T-cell counts (CD4) were performed by flow cytometry (BD, USA).

The Stanford HIVdb program version 8.4 (https:// hivdb.stanford.edu/hivdb/by-mutations) was used to interpret the genotype resistance. The mutations were analyzed individually using a list provided by the International AIDS Society (IAS) in 2017, [16] and the Stanford HIVdb program and categorized as mutations associated with NRTI(t), NNRTI and major and accessory mutations for protease inhibitors (PI). Forty-eight weeks after switching to second-line therapy, virologic suppression was considered successful when an undetectable viral load was found by the given method. Viral load values made available 60 days before or after the date of completion (for the 48 weeks) were considered. The time on ARVs was the period between the beginning of the first ARV regimen and the performance of the genotyping test. The time in virologic failure was the period between virologic failure detection (two consecutive viral loads above 1000 copies/ml) and the switch to the salvage regimen.

The genotypic sensitivity score (GSS) was calculated individually only for the drugs used by each patient in the salvage regimen. A value of 1 was attributed to drugs with full activity, 0.75 for a low potential resistance level, 0.5 for a resistance level, 0.25 for an intermediate resistance level and zero if the drug showed a lack of activity.

SPSS 13.0 (Statistical Package for the Social Sciences) for Windows and Excel 2010 were used for the statistical analysis. The results are presented in the tables with 
their respective absolute and relative frequencies. The mean or median values for the quantitative variables were calculated according to the normality of their distribution. The normality of the quantitative variables was tested using the Kolmogorov-Smirnov test.

We tested for the presence of an association using the chi-square test and Fisher's exact test for categorical variables. To identify the predictive factors that independently influenced virologic suppression and the number of mutations associated with $\operatorname{NRTI}(t) s$, we used the STATA/SE 12.0 programs. For the multivariate analysis, the Poisson regression model was used, taking into account the variables that obtained significance $\leq 0.20$ in the bivariate analysis. The prevalence ratio was calculated with a $95 \%$ confidence interval. A $p<0.05$ was considered statistically significant. Poison-regression was chosen as excellent alternative to estimate the adjusted prevalence ratio for confounding variables in cross-sectional studies compared to Cox and log-binominal logistic regression. The study was approved by the institutional ethics committee (CEP-CCS-UFPE/1.985.922).

\section{Results}

A total of 534 medical records were evaluated, of which 270 were excluded due to a lack of genotyping tests when patients switched ARVs after the first virologic failure. In 59 medical records, there was no selective pressure during genotyping. Therefore, the absence of mutation does not represent reality. Thus, 59 patients were excluded. Non-adherence to ARV use at the time of genotyping was recorded in the medical charts of the 59 excluded patients with absence of resistance-associated mutations. Furthermore, 21 patients were not either illegible or had insufficient data.

A total of 184 patients were included in the first virologic failure for analysis. The majority of the participants were male $(73.4 \%)$ and the mean age at virologic failure was $41( \pm 9.4)$ years. The median CD4 $(n=155)$ and VL $(n=141)$ pre-ARV were 176 cells $/ \mathrm{m} 3$ and 130,000 copies/ml, respectively.

This sample is representative considering the limited resources scenario. It represents a decade of genotyping in the first virologic failure in Pernambuco, Northeast Brazil. In 2016, we were able to access genotyping easily. Between 2006 and 2016, there was therapeutic rescue without genotyping due to the logistic difficulty in this region of Brazil. Therefore, more than $50 \%$ of the sample was excluded by changing the scheme without genotyping.

Factors associated with mutations, immunovirologic and ARV characteristics at the time of genotyping

The genotypic, immunovirologic and ARV characteristics at the time of genotyping are described in Table 1 .
Table 1 Demographic and clinical characteristics of study participants

\begin{tabular}{|c|c|c|}
\hline Variables & $N$ & $\%$ \\
\hline Age (years) (mean $\pm S D)$ & 41,1 & \\
\hline \multicolumn{3}{|l|}{ Gender } \\
\hline Male & 135 & 73,4 \\
\hline Female & 49 & 26,6 \\
\hline Baseline CD4 count, median (Q1; Q3) & 234 & \\
\hline \multicolumn{3}{|l|}{ CD4 } \\
\hline$<200$ & 78 & 42,4 \\
\hline 200 a 350 & 50 & 27,2 \\
\hline$>350$ & 47 & 25,5 \\
\hline Data unavailable & 9 & 4,9 \\
\hline VL (copies/ml), median (Q1; Q3) & \multicolumn{2}{|c|}{$19.812,5(7.036,0 ; 78.674,2)$} \\
\hline \multicolumn{3}{|l|}{ VL (copies/ml) } \\
\hline$\leq 10.000$ & 59 & 32,1 \\
\hline$>10.000$ a 100.000 & 75 & 40,7 \\
\hline$>100.000$ & 37 & 20,1 \\
\hline Data unavailable & 13 & 7,1 \\
\hline$\Delta \mathrm{t}$ on ART (months), median (Q1;Q3) & 54,5 & \\
\hline $\begin{array}{l}\Delta \mathrm{t} \text { in virologic failure } \\
\text { (months), median }(\mathrm{Q} 1 ; \mathrm{Q} 3)\end{array}$ & 17,0 & \\
\hline NRTI in failing regimen & 184 & 100,0 \\
\hline AZT/3TC & 126 & 68,5 \\
\hline TDF/3TC & 48 & 26,1 \\
\hline Others & 10 & 5,4 \\
\hline NNRTI in failing regimen & 155 & 84,2 \\
\hline EFV & 135 & 87,1 \\
\hline NVP & 20 & 12,9 \\
\hline PI in failing regimen & 29 & 15,8 \\
\hline$L P V / r$ & 16 & 55,2 \\
\hline ATV/r ou ATV $400 \mathrm{mg}$ & 12 & 41,4 \\
\hline Outros & 1 & 3,4 \\
\hline Viral Subtype & 171 & 92,9 \\
\hline B & 139 & 81,3 \\
\hline $\mathrm{F}$ & 31 & 18,1 \\
\hline $\mathrm{BF}$ & 1 & 0,4 \\
\hline
\end{tabular}

$V L=$ viral load, $A R T$ antiretroviral therapy, NNRT/s nonnucleoside reverse transcriptase inhibitors, NRT/s nucleoside/nucleotide reverse transcriptase inhibitors, AZT zidovudine; 3TC lamivudine, TDF tenofovir, EFV: efavirenz, $N V P$ nevirapine, $P /$ protease inhibitor; $L P V / r$ lopinavir/ritonavir, $A T V / r$ atazanavir/ritonavir

The NRTI $(t)$-associated mutation M184 V/I emerged in $78.4 \%$ of the subtype B sequences and in $21.6 \%$ of the non-B subtype sequences $(p=0.009)$. Most individuals $(89.7 \%)$ exhibited at least one mutation for $\operatorname{NRTI}(t)$. The association of the presence of $\geq 3 \operatorname{NRTI}(\mathrm{t})$-associated mutations with CD4 pre-ARVs $<200$ cell $/ \mathrm{mm} 3(66.7 \%$ vs $33.3 \%$ for $\mathrm{CD} 4$ pre-ARVs $\geq 200$, prevalence ratio $[\mathrm{PR}]=$ 
$1.52, \mathrm{CI}=1.00-2.31, p=0.041)$, with $\mathrm{CD} 4$ at the time of genotyping $<200$ cells $/ \mathrm{mm} 3(59.4 \%$ vs $23.4 \%$ for CD4 200-350 vs $17.2 \%$ for $\mathrm{CD} 4>350, \mathrm{PR}=2.04, \mathrm{CI}=1.18-$ $3.55, p<0.011)$, and with a time on ARV of greater than 36 months $(81.2 \%$ vs $18.8 \%$ for $\Delta t<36$ months, $p=0.003)$ were significant, according to Table 2 . In addition, a VL of
10,000-100,000 copies/ml was associated with the highest number of $\operatorname{NRTI}(\mathrm{t})$-associated mutations (Table 2).

After analysis using the Poisson regression model (Table 3), only patients who were on ARVs for more than 36 months until genotyping $(\mathrm{PR}=2.43,95 \% \mathrm{CI}=$ 1.38-4.28, $p=0.002$ ) and who developed VL at the time

Table 2 Risk factors associated with HIV-1 drug resistance

\begin{tabular}{|c|c|c|c|c|c|}
\hline \multicolumn{6}{|l|}{ Number of resistance mutations } \\
\hline Factors & $\geq 3 n(\%)$ & $<3 n(\%)$ & PR & PR 95\% IC & $P$-value \\
\hline Age (years) & & & & & $0,806^{\mathrm{a}}$ \\
\hline $18-30$ & $7(10,1)$ & $11(11,5)$ & 0,90 & $0,49-1,66$ & \\
\hline $31-50$ & $52(75,4)$ & $68(70,8)$ & 1,00 & - & \\
\hline$>50$ & $10(14,5)$ & $17(17,7)$ & 0,85 & $0,50-1,46$ & \\
\hline Gender & & & & & $0,476^{\mathrm{a}}$ \\
\hline Male & $53(76,8)$ & $69(71,9)$ & 1,17 & $0,75-1,81$ & \\
\hline Female & $16(23,2)$ & $27(28,1)$ & 1,00 & - & \\
\hline Viral subtype & & & & & $0,771^{a}$ \\
\hline B & $50(80,6)$ & $74(78,7)$ & 1,00 & - & \\
\hline No-B & $12(19,4)$ & $20(21,3)$ & 0,93 & $0,57-1,53$ & \\
\hline VL before ART (copies/ml) & & & & & $0,570^{b}$ \\
\hline$\leq 10.000$ & $4(7,5)$ & $3(4,3)$ & 1,00 & - & \\
\hline$>10.000$ a 100.000 & $17(32,1)$ & $27(38,6)$ & 0,68 & $0,32-1,42$ & \\
\hline$>100.000$ & $32(60,4)$ & $40(57,1)$ & 0,78 & $0,39-1,55$ & \\
\hline CD4 before ART & & & & & $0,041^{a}$ \\
\hline$<200$ & $40(66,7)$ & $39(49,4)$ & 1,52 & $1,00-2,31$ & \\
\hline$\geq 200$ & $20(33,3)$ & $40(50,6)$ & 1,00 & - & \\
\hline VL in virologic failure (copies/ml) & & & & & $0,042^{a}$ \\
\hline$\leq 10.000$ & $15(24,6)$ & $38(71,7)$ & 1,00 & - & \\
\hline$>10.000$ a 100.000 & $34(55,7)$ & $33(36,3)$ & 1,79 & $1,10-2,92$ & \\
\hline$>100.000$ & $12(19,7)$ & $20(22,0)$ & 1,33 & $0,71-2,46$ & \\
\hline CD4 in virologic failure & & & & & $0,011^{a}$ \\
\hline$<200$ & $38(59,4)$ & $33(35,9)$ & 2,04 & $1,18-3,55$ & \\
\hline $200-350$ & $15(23,4)$ & $28(30,4)$ & 1,33 & $0,69-2,56$ & \\
\hline$>350$ & $11(17,2)$ & $31(33,7)$ & 1,00 & - & \\
\hline ART regímen at NRTI baseline & & & & & $0,189^{a}$ \\
\hline TDF & $12(17,4)$ & $25(26,0)$ & 1,00 & - & \\
\hline No-TDF & $57(82,6)$ & $71(74,0)$ & 1,37 & $0,83-2,27$ & \\
\hline Time to virologic failure (months) & & & & & $0,221^{\mathrm{a}}$ \\
\hline$<12$ & $13(19,4)$ & $28(30,4)$ & 1,00 & - & \\
\hline $12-24$ & $25(37,3)$ & $34(37,0)$ & 1,34 & $0,78-2,29$ & \\
\hline$>24$ & $29(43,3)$ & $30(32,6)$ & 1,55 & $0,92-2,60$ & \\
\hline Time on ART (months) & & & & & $0,003^{a}$ \\
\hline$\leq 36$ & $13(18,8)$ & $39(40,6)$ & 1,00 & - & \\
\hline$>36$ & $56(81,2)$ & $57(59,4)$ & 1,98 & $1,19-3,29$ & \\
\hline
\end{tabular}

$A R T$ antiretroviral therapy, $P R$ prevalence ratio, $C l$ confidence interval, $V L$ viral load, cell $T C D 4 C D 4 T$ cell count, TDF tenofovir, NRTIs nucleoside/nucleotide reverse transcriptase inhibitors

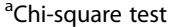

${ }^{\mathrm{b}}$ Fisher's exact test 
Table 3 Analysis using the poisson regression model

\begin{tabular}{|c|c|c|c|}
\hline Variables & $P R$ & PR 95\% Cl & $P$-value \\
\hline \multicolumn{4}{|c|}{ CD4 before ARTs (cells $/ \mathrm{mm}^{3}$ ) } \\
\hline$<200$ & 1,46 & $0,95-2,24$ & 0,084 \\
\hline$\geq 200$ & 1,00 & - & \\
\hline \multicolumn{4}{|l|}{ HIV AIDS (Auckl) } \\
\hline$\geq 10.000$ & 1,00 & - & \\
\hline$>10.000$ a 100.000 & 2,09 & $1,25-3,50$ & 0,005 \\
\hline$>100.000$ & 2,20 & $1,14-4,27$ & 0,018 \\
\hline \multicolumn{4}{|l|}{ Time to failure (months) } \\
\hline$\leq 36$ & 1,00 & - & 0,002 \\
\hline$>36$ & 2,43 & $1,38-4,28$ & \\
\hline
\end{tabular}

$P R$ prevalence ratio, $C l$ confidence interval, $C D 4 C D 4+T$ cell count, $V L$ viral load

of genotyping of 10,000-100,000 copies $/ \mathrm{ml} \quad(\mathrm{PR}=2.09$ $95 \% \mathrm{CI}=1.25-3.50, p=0.005)$ and $>100,000$ copies $/ \mathrm{ml}$ $(\mathrm{PR}=2.20,95 \% \mathrm{CI}=1.14-4.27, \mathrm{p}=0.005)$ had a higher risk of having $\geq 3$ NRTI ( $t$ )-associated mutations.

There was a trend towards the emergence of three or more thymidine-associated mutations (TAMs) when the time on ARVs was greater than 36 months $(92 \%$ vs $8 \%$ for $\Delta \mathrm{t}$ on ARVs $\leq 36$ months, $p=0.051)$. K65R emerged in $7.6 \%$ of 184 genotyping tests (Fig. 1) and was observed in $27.1 \%$ of patients who were exposed to TDF/ 3TC. Mutations in the K103 codon were observed in $65.8 \%(n=121 / 184)$ of the genotyping tests. Among those who used NNRTI, this mutation occurred in $78.0 \%(n=121 / 155)$. The NNRTI-associated mutation 90IV was more frequent in the non-B subtype $(57.1 \%$ vs $42.9 \%$ for subtype $B, p=0.024$ ) and the $190 \mathrm{AS}$ was most prevalent for etravirine.

Considering the 29 patients who used PI, 55.2\% $(n=16)$ were on lopinavir/ritonavir $(\mathrm{LPV} / \mathrm{r})$ and $41.4 \% \quad(n=12)$ were on atazanavir (ATV) (Table 1). The PI-associated major and accessory mutations were $82 \mathrm{AF}(51.7 \%)$ and 10IFV (62\%), respectively.

The PI-associated major mutation 54VL emerged frequently in subtype B sequences $(58.3 \%$ vs $41.7 \%$ for non-B subtype, $p=0.05)$, as did the PI-associated accessory mutations 10IFV (69\% vs $31 \%$ for non-B subtype, $p=0.019)$ and $20 \mathrm{RT}(60 \%$ vs $40 \%$ for non-B subtype, $p=0.010$ ).

The total number of mutations was significantly equal to or greater than seven among the users who had a CD4 count below 200 cells $/ \mathrm{m} 3$ at the time of genotyping (52.9\% vs $27.6 \%$ for CD $4200-350$ cells $/ \mathrm{m} 3$ vs $19.5 \%$ for CD4 > 350 cells $/ \mathrm{m} 3, p=0.045)$.

\section{Salvage therapy characteristics}

There was a loss of follow-up in eight (4.3\%) patients after the genotyping test was performed. Thus, 176 (95.7\%) patients switched to the salvage regimen. Of these individuals, 109 (61.9\%) patients used TDF/3TC as the $\operatorname{NRTI}(t)$, followed by $28(15.9 \%)$ who used TDF/ AZT(zidovudine)/3TC and 27 (15.3\%) AZT/3TC. Only nine $(5.1 \%)$ individuals did not have $\operatorname{NRTI}(t)$ s included in their salvage regimen.

PIs were present in the salvage regimen of $99.4 \%$ of the individuals; only one patient did not use PI. LPV/r was the most frequently prescribed (48.5\%) followed by ATV/r (33.1\%). Integrase inhibitors made up the salvage regimen of 35 (19.9\%) individuals. Raltegravir (RAL) was the most frequently used one $(n=32)$. When the salvage regimen consisted of two active drugs $(\mathrm{GSS}=2), 79.5 \%$ of this population showed genotyping with less than three $\operatorname{NRTI}(\mathrm{t})$-associated mutations $(79.5 \%$ vs $20.5 \%$ for $\geq 3 \operatorname{NRTI}(\mathrm{t})$-associated mutations, $p<0.000$ ).

The susceptibility of etravirine was not associated with the use of EFV or nevirapine (NVP) or with the number of NNRTI-associated mutations. This treatment remained fully active in $63.2 \%$ of the sequences among

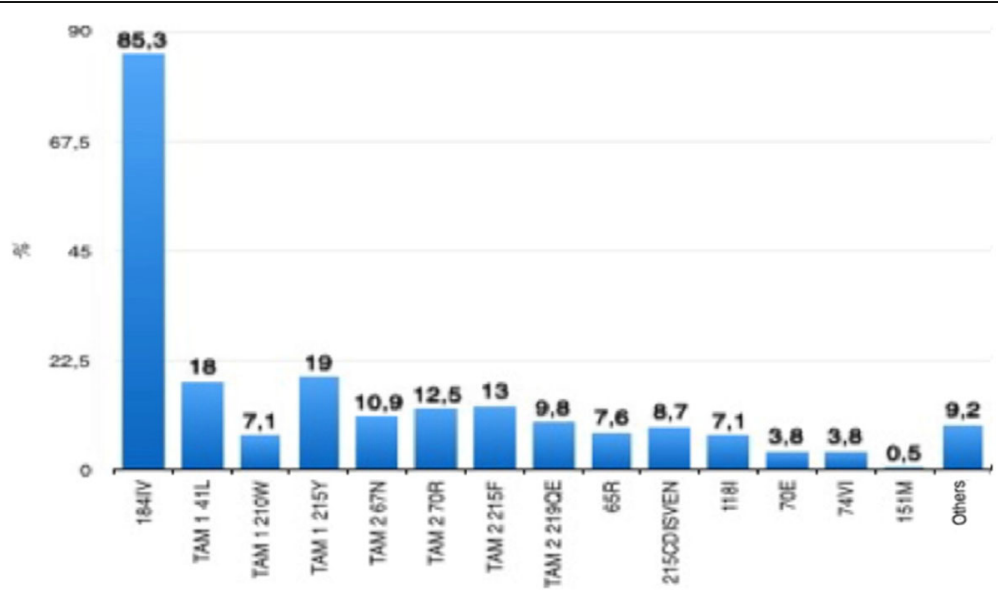

Fig. 1 The prevalence of drug resistance to NRTI among 184 HIV-1 infected patients with virologic failure 
the patients who experienced a failed NNRTI therapy. We found a similar susceptibility of AZT and TDF (64.2\% vs $65.9 \%)$. Among the PI/r users, darunavir/ritonavir (DRV/r) showed the highest percentage of sensitivity (69\%), and ATV/r experienced the highest percentage of resistance (79.3\%).

Most of the salvage regimens showed GSS equal to two $(42.6 \%)$ or greater than two $(44.3 \%)$. We found that in most of the regimens with a GSS greater than 2, the patient was in virologic failure for more than 24 months ( $46 \%$ vs $30.8 \%$ for $\Delta \mathrm{t}$ in virologic failure $12-24$ months vs $23.2 \%$ for $\Delta \mathrm{t}$ in virological failure $<12$ months, $p=$ $0.013)$ and on ARV for more than 36 months $(76.9 \%$ vs $23.1 \%$ for $\Delta \mathrm{t}$ in ARV 36 months, $p=0.004$ ).

When virologic failure occurred during LPV/r use, the GSS of the salvage therapy regimen was significantly higher than two $(85.7 \%$ vs $14.3 \%$ for $\mathrm{GSS}=2$ vs $0 \%$ for GSS $<2, p=0.001)$. The significant majority of TDF users in virologic failure were salvaged with an ARV regimen with a GSS equal to two $(62.2 \%$ vs $27.0 \%$ for GSS $>2$ vs $10.8 \%$ for GSS $<2, p=0.023$ ).

\section{Predictors of undetectable viral loads and CD4 T-cell count variation at $\mathbf{4 8}$ weeks after the onset of the salvage regimen}

Of the 176 patients who received documented salvage therapy prescriptions, we were able to obtain the VL value 48 weeks after switching ARVs for 159 (90.3\%). Of these, 67.3\% $(n=107)$ experienced virologic suppression and $11.3 \%$ did not reach an undetectable VL but had below 400 copies $/ \mathrm{ml}$. The majority of the population with undetectable VL had more than 36 months of ARV use until genotyping $(73.8 \%$ vs $26.2 \%$ for 36 months, $p=0.022)$, and $42.0 \%$ were in virologic failure for 12 to 24 months $(42.0 \%$ vs $34.6 \%$ for $>$ 24 months vs $23.4 \%$ for $<12$ months, $p=0.029$ ) (Table 4).

The number of NRTI(t)-associated mutations did not affect virologic suppression ( $9.3 \%$ for zero NRTI(t)-associated mutations vs $48.6 \%$ for $1-2 \operatorname{NRTI}(t)$-associated mutations vs $42.1 \%$ for $\geq 3 \mathrm{NRTI}(\mathrm{t})$-associated mutations, $p=0.179$ ) (Table 5).

After an analysis with the Poisson regression model, only being on ARVs for more than 36 months until genotyping was a protective factor for a detectable viral load ( $P R \quad 0.6,95 \% \mathrm{CI}=0.39-0.92, \mathrm{p}=0.02$ ) 48 weeks after switching to the salvage regimen (Table 6).

For the 153 patients with documented CD4 after 48 weeks, the median was 376 cells/mm3 (Q1 246; Q3 553) and the median CD4 gain was 125 cells/mm3 (Q1 47; Q3 243). In the population with virologic success, the variation in the CD4 gain above 100 cells $/ \mathrm{mm} 3$ was significant when the VL at the time of genotyping was $10,000-100,000$ copies $/ \mathrm{ml}(69.8 \%$ vs $30.2 \%$ for variation < 100 cells/mm3, $p=0.047)$ and when the $\mathrm{CD} 4$ at the time of genotyping was below 200 cells $/ \mathrm{mm} 3$ (81.4\% vs $18.6 \%$ for CD $4<100$ cells $/ \mathrm{mm} 3 p=0.010$ ).

\section{Discussion}

After evaluating 184 genotyping tests from patients during the first virologic failure, we found a higher prevalence of subtype B, of the M184 V/I and K103 N mutations, as well as a high frequency of $\operatorname{NRTI}(t)$ and NNRTI-associated mutations, with no impact on virologic suppression. We observed that the salvage therapy regimen was predominantly composed of $\mathrm{PI} / \mathrm{r}$ and $\operatorname{NRTI}(t) s$, with virologic success in most cases. Subtype $B$ remains the most common in Pernambuco [17-19] and in Brazil [11], except in the south, where subtype C [21] is predominant. There has been an increase in the proportion of recombinant forms in Rio de Janeiro [22] and subtype F in Minas Gerais [40].

The elevated presence of M184 codon mutations is expected and arises as a consequence of the use of lamivudine as part of all the first-line regimens in our study. This drug confers a high level of resistance to cytosine analogs (lamivudine and emtricitabine), a low level of resistance to abacavir, and the increased susceptibility of zidovudine and TDF. In addition, it decreases the replication capacity of HIV-1 [23, 24]. Its presence has been associated with virologic success [10], but we did not observe this success in the present study.

Similar to our results, the high prevalence of M184 V/I mutations was reported in several regions of Brazil [11, 25, 40], in Sub-Saharan Africa [26] and in Asia [27], but to a lesser extent in western Europe [28]. This difference can be explained by the use of emtricitabine in European countries and by the use of lamivudine in low- and middle-income settings. However, in a recent meta-analysis [29], lamivudine and emtricitabine were clinically equivalent. All the genotype sequences of the non-B subtype ( $F$ and $B F$ ) had the M184 V/I mutation, probably due to the high prevalence of this mutation and the very low frequency of non-B subtypes in our study.

We found no association between the number of $\operatorname{NRTI}(t)$-associated mutations and the ARVs used at the time of genotyping, including ARV regimens with or without TDF. There are studies showing a greater number of resistance-associated mutations among AZT [30] and TDF users [10, 31]. However, those studies had populations with different characteristics, especially with regard to subtype prevalence. A higher number of mutations with a TDF-based regimen was reported for both the $\mathrm{B}$ subtype ${ }^{10}$ as well as with the $\mathrm{C}$ subtype [33]. The association between a high number of NRTI(t)-associated mutations with $\mathrm{CD} 4$ pre-ARV and at the time of genotyping of $>200$ cells $/ \mathrm{mm} 3$ suggests a late 
Table 4 Characteristics related to the irrigation regimen, ART time and virological failure time associated with virological suppression after 48 weeks from the start of the rescue scheme

\begin{tabular}{|c|c|c|c|c|c|}
\hline \multicolumn{6}{|l|}{ Viral load (VL) } \\
\hline Characteristics & $\begin{array}{l}\text { Detectable } \\
n(\%)\end{array}$ & $\begin{array}{l}\text { Undetectable } \\
n(\%)\end{array}$ & PR & PR 95\% IC & $P$-value \\
\hline Time to virologic failure (months) & & & & & $0,029^{a}$ \\
\hline$<12$ & $22(42,3)$ & $25(23,4)$ & 1,00 & - & \\
\hline $12-24$ & $13(25,0)$ & $45(42,0)$ & 0,48 & $0,27-0,84$ & \\
\hline$>24$ & $17(32,7)$ & $37(34,6)$ & 0,67 & $0,41-1,11$ & \\
\hline$\Delta \mathrm{t}$ on ART (months) & & & & & $0,022^{a}$ \\
\hline$\leq 36$ & $23(44,2)$ & $28(26,2)$ & 1,00 & - & \\
\hline$>36$ & $29(55,8)$ & $79(73,8)$ & 0,60 & $0,39-0,92$ & \\
\hline ART rescue NRTI & & & & & $0,711^{\mathrm{b}}$ \\
\hline TDF/3TC & $36(69,2)$ & $62(57,9)$ & 1,00 & - & \\
\hline $\mathrm{AZT} / 3 \mathrm{TC}$ & $7(13,5)$ & $18(16,8)$ & 0,76 & $0,39-1,50$ & \\
\hline TDF/AZT/3TC & $7(13,5)$ & $19(17,8)$ & 0,73 & $0,37-1,45$ & \\
\hline DDI/3TC & $0(0,0)$ & $1(0,9)$ & - & - & \\
\hline $\mathrm{ABC} / 3 \mathrm{TC}$ & $1(1,9)$ & $1(0,9)$ & 1,36 & $0,33-5,58$ & \\
\hline NNRTI & $1(1,9)$ & $6(5,6)$ & 0,39 & $0,00-2,43$ & \\
\hline ART rescue $\mathrm{PI}$ & & & & & $0,013^{b}$ \\
\hline $\mathrm{LPV} / \mathrm{r}$ & $24(46,1)$ & $55(51,5)$ & 2,13 & $0,71-6,39$ & \\
\hline ATV $/ r$ & $20(38,5)$ & $33(30,8)$ & 2,64 & $0,88-7,96$ & \\
\hline $\mathrm{DRV} / \mathrm{r}$ & $3(5,8)$ & $18(16,8)$ & 1,00 & - & \\
\hline $\mathrm{FPV} / \mathrm{r}$ & $5(9,6)$ & $1,(0,9)$ & 5,83 & $1,93-17,65$ & \\
\hline ART rescue with RAL & & & & & $0,050^{a}$ \\
\hline YES & $5(9,6)$ & $24(22,4)$ & 1,00 & - & \\
\hline NO & $47(90,4)$ & $83(77,6)$ & 2,10 & $0,91-4,81$ & \\
\hline GSS & & & & & $0,947^{\mathrm{a}}$ \\
\hline$<2$ & $8(15,4)$ & $15(14,0)$ & 1,11 & $0,57-2,14$ & \\
\hline 2 & $22(42,3)$ & $44(41,1)$ & 1,06 & $0,65-1,72$ & \\
\hline$>2$ & $22(42,3)$ & $48(44,9)$ & 1,00 & - & \\
\hline
\end{tabular}

${ }^{a}$ Chi-square test ${ }^{\mathrm{b}}$ Fisher's exact test; $P R$ prevalence ratio, $C$ C Confidence interval, NNRTI nonnucleoside reverse transcriptase inhibitors, NRTI nucleoside/nucleotide reverse transcriptase inhibitors, $A Z T$ zidovudine, TAM analogous thymidine mutation, 3TC lamivudine, TDF tenofovir, $P I$ protease inhibitor, $L P V / r$ lopinavir/ritonavir, $A T V / r$ - atazanavir/ritonavir, DRV/r Darunavir/ritonavir, FPV/r fosamprenavir/ritonavir, GSS genotypic sensitivity score

diagnosis of PLHIV in our population, with an impact on the genotypic profile. These factors did not remain significant after the analysis with the Poisson regression model.

The K103 N/S mutation was documented in most genotypic sequences, due to the frequent use of EFV as the primary NNRTI in the first-line therapy for more than a decade in Brazil. These findings are similar to the national data [10-12] and data from low- and middle-income countries [14, 15, 26, 27]. The susceptibility of etravirine, a second-generation NNRTI, was not influenced by experiencing a long period of time in virologic failure while using EFV or NVP, or by the number of NNRTI-associated mutations.
This analysis was hampered by the small number of NVP users at the time of virologic failure. However, some studies [32-34] have shown that NVP-containing ARVs have repercussions on the response to etravirine for selecting the Y181C and G190A mutations, whereas the K103 mutation associated with EFV does not interfere with etravirine susceptibility.

The median time from ARV therapy to genotyping was similar to that of recent studies in Brazil [10], 10 Africa and Europe [36]. After the Poisson regression model analysis, remaining on ARV for more than 36 months until genotyping was the only factor that impacted the virologic response 48 weeks after the onset of salvage therapy, appearing as a protective 
Table 5 Genotypic and immuno-trophic characteristics at the time of genotyping associated with virological suppression after 48 weeks of initiation of the rescue scheme

\begin{tabular}{|c|c|c|c|c|c|}
\hline \multicolumn{6}{|l|}{ Viral Load (VL) } \\
\hline Characteristics & $\begin{array}{l}\text { Detectable } \\
n(\%)\end{array}$ & $\begin{array}{l}\text { Undetectable } \\
n(\%)\end{array}$ & $P R$ & PR 95\% IC & $P$-value \\
\hline Age (years) & & & & & $0,662^{\mathrm{a}}$ \\
\hline $18-30$ & $6(11,5)$ & $13(12,2)$ & 0,92 & $0,45-1,86$ & \\
\hline $31-50$ & $40(76,9)$ & $76(71,0)$ & 1,00 & - & \\
\hline$>50$ & $6(11,5)$ & $18(16,8)$ & 0,73 & $0,35-1,52$ & \\
\hline Gender & & & & & $0,385^{\mathrm{a}}$ \\
\hline Male & $36(69,2)$ & $81(75,7)$ & 0,81 & $0,50-1,29$ & \\
\hline Female & $16(30,8)$ & $26(24,3)$ & 1,00 & - & \\
\hline VL on genotypic result (copies/ml) & & & & & $0,752^{\mathrm{a}}$ \\
\hline$\leq 10.000$ & $18(35,3)$ & $36(34,3)$ & 1,00 & - & \\
\hline$>10.000$ a 100.000 & $20(39,2)$ & $47(44,7)$ & 0,90 & $0,53-1,52$ & \\
\hline$>100.000$ & $13(25,5)$ & $22(21,0)$ & 1,11 & $0,63-1,98$ & \\
\hline CD4 on genotypic result (cells/mm3) & & & & & $0,796^{\mathrm{a}}$ \\
\hline$<200$ & $20(38,5)$ & $45(42,9)$ & 0,95 & $0,54-1,66$ & \\
\hline $200-350$ & $18(34,6)$ & $31(29,5)$ & 1,13 & $0,64-1,99$ & \\
\hline$>350$ & $14(26,9)$ & $29(27,6)$ & 1,00 & - & \\
\hline Number of NRTI resistance mutations & & & & & $0,179^{a}$ \\
\hline zero & $6(11,6)$ & $10(9,3)$ & 1,00 & - & \\
\hline$<3$ & $32(61,5)$ & $52(48,6)$ & 1,02 & $0,51-2,02$ & \\
\hline$\geq 3$ & $14(26,9)$ & $45(42,1)$ & 0,63 & $0,29-1,38$ & \\
\hline $\mathrm{N}^{\circ}$ of thymidine analogue mutation & & & & & $0,058^{a}$ \\
\hline zero & $35(67,3)$ & $54(50,4)$ & 1,00 & - & \\
\hline$<3$ & $14(26,9)$ & $34(31,8)$ & 0,74 & $0,45-1,24$ & \\
\hline$\geq 3$ & $3(5,8)$ & $19(17,8)$ & 0,35 & $0,12-1,02$ & \\
\hline Number of NNRTI resistance mutations & & & & & $0,113^{\mathrm{a}}$ \\
\hline$\leq 2$ & $32(61,5)$ & $79(73,8)$ & 1,00 & - & \\
\hline$>2$ & $20(38,5)$ & $28(26,2)$ & 1,45 & $0,93-2,25$ & \\
\hline Number of PI resistance mutations & & & & & $1,000^{b}$ \\
\hline$\leq 2$ & $4(80,0)$ & $14(77,8)$ & 1,00 & - & \\
\hline$>2$ & $1(20,0)$ & $4(22,2)$ & 0,90 & $0,13-6,35$ & \\
\hline M184 V/I mutation & & & & & $0,693^{\mathrm{a}}$ \\
\hline Yes & $44(84,6)$ & $93(86,9)$ & 1,00 & - & \\
\hline no & $8(15,4)$ & $14(13,1)$ & 1,13 & $0,62-2,07$ & \\
\hline
\end{tabular}

${ }^{a}$ Chi-square test ${ }^{b}$ Fisher's exact test, $P R$ prevalence ratio, $C$ Confidence interval, CD4: CD4 T cells, CV viral load, NNRTI non-nucleoside reverse transcriptase inhibitor, $P$ I protease inhibitor, NRTI nucleoside reverse transcriptase inhibitor

factor for a detectable viral load. To understand the impact of time on ARV on virologic success, factors that could influence treatment adherence would have to be identified and controlled, because the major cause of acquired virologic failure is poor adherence to ARVs [42].

A shorter time on ARV is used as the best scenario for adherence in the calculation of odds ratio in studies that seek to understand the risk factors for treatment adherence. However, after association testing, its impact on adherence is not always confirmed [43]. This finding is probably observed because adherence is a dynamic behavior and varies over time for the same individual, and it is affected by diverse factors such as psychosocial-, ARV- and clinical scenario-related factors. This finding explains why the time on ARV may be a risk or protective factor for poor adherence, with an impact on virologic success [42]. 
Table 6 Poisson model for viral load detectable after 48 weeks of onset of rescue scheme

\begin{tabular}{|c|c|c|c|}
\hline Variables & $\mathrm{PR}^{\mathrm{a}}$ & PR IC95\% ${ }^{\mathrm{b}}$ & $p$-value \\
\hline \multicolumn{4}{|c|}{${ }^{c} \Delta \mathrm{t}$ on $\mathrm{ARV}$ (months) } \\
\hline$\leq 36$ & 1,00 & - & 0,020 \\
\hline$>36$ & 0,60 & $0,39-0,92$ & \\
\hline
\end{tabular}

aPR: prevalence ratio ${ }^{\mathrm{b}} \mathrm{C}$ : Confidence interval ${ }^{\mathrm{c}}$ time variation on antiretroviral therapy

By contrast, more than 36 months on ARV increased the risk for the selection of three or more NRTI(t)-associated mutations, although a longer time in virologic failure did not generate the same outcome. According to the virologic failure criterion of this study, individuals with low VL ( $><1000$ copies/ml) were not considered to be in virologic failure, because the genotyping tests available in Brazil during the data collection period were not able to expand the genetic material when the VL was < 1000 copies/ml. However, there is evidence that having a VL of $>200$ copies $/ \mathrm{ml}$ increases the risk for virologic failure and may lead to mutation accumulation [44]. Therefore, it is possible that many individuals who are on ARV for a long period of time (>36 months) had low VL but were not diagnosed with virologic failure, accumulating mutations.

We observed that the presence of $\operatorname{NRTI}(t)$-associated mutations or TAMs at the first virologic failure did not interfere with virologic suppression 48 weeks after the switch to a second-line therapy with $\operatorname{NRTI}(t)$ s combined with $\mathrm{PI} / \mathrm{r}$. This finding is not only due to the high potency of $\mathrm{PI} / \mathrm{r}$ or to the direct activity of $\operatorname{NRTI}(\mathrm{t}) \mathrm{s}$, and it may reflect an effect of the NRTI(t)s on viral fitness [35]. This finding is consistent with the results of three large randomized controlled trials in which patients with extensive resistance to reverse transcriptase evolved with virologic success after salvage therapy based on $\operatorname{NRTI}(t)$ with $\mathrm{PI} / \mathrm{r}$ [13-15].

We found no difference in the virologic response between regimens with an individual GSS of less than two and those greater than or equal to two, confirming the hypothesis that there is no difference between active, partially active or inactive $\operatorname{NRTI}(t) s$ in terms of virologic success [35]. In the EARNEST study [14], the group receiving inactive or partially active $\mathrm{NRTI}(\mathrm{t}) \mathrm{s}$ exhibited viral load suppression that was similar to if not better than that exhibited by the group receiving the regimen containing a fully active drug from a new class, and it was superior to that exhibited by the group using only a protease inhibitor.

It is possible that pharmacokinetic characteristics optimize the benefits of NRTI(t)s even if inactive. Thus, ARVs with a long intracellular half-life, such as TDF and lamivudine, may help the PI/r to maintain viral suppression. This effect is independent of the drug activity [41].
We were able to define the time in virologic failure until the switch to second-line therapy. Surprisingly, most of the patients with undetected viral loads were in virologic failure for more than 12 months. Because the time under virologic failure did not interfere with the number of NRTI(t)-associated mutations or TAMs in our study, we can suggest that the resistance-associated mutations arose during the first months of virologic failure. In the EUROSIDA study [37], a high number of TAM-1 mutations was observed within one year of failure, with a lower accumulation rate than what was predicted among those who stayed on the failing regimen.

The total absence of ARV selective pressure during part of the virologic failure period is another way to explain why the longer virologic failure time did not influence the number of NRTI(t)-associated mutations or TAMs. The complete withdrawal of ARVs generates fewer resistance-associated mutations than does the maintenance of sub-therapeutic doses [9]. It was not possible to determine whether the study participants were kept on sub-therapeutic doses or if they completely abandoned the treatment when they were in virologic failure.

When we analyzed the virologic response and ARVs used in salvage therapy, we observed that there was no difference between the patients who used AZT or TDF or both. The use of LPV/r was significant among those who experienced virologic success, probably because it was the most frequently prescribed PI during the study period, as directed by the Brazilian Ministry of Health. Among users of $\mathrm{DRV} / \mathrm{r}$ or RAL, the majority achieved virologic success, although they were smaller in absolute numbers.

$\mathrm{DRV} / \mathrm{r}$ is the newest PI and has a high genetic barrier, in addition to fewer adverse effects than LPV/r, possessing activity even with a protease mutation [38]. When the protease is not intact, adding a new ARV class is critical. This class has often been the integrase inhibitor [39]. It should be noted that this study was not designed to assess the individual power of each regimen. Among those who reached an undetectable VL, a CD4 gain above 100 cells $/ \mathrm{mm} 3$ was significant in subjects with CD4 at the time of genotyping $>200$ cells/mm3, demonstrating that when there is adherence, a significant immunologic gain is possible even in patients with a low immunologic reserve and extensive resistance in reverse transcriptase.

Our primary limitation was the difficulty in establishing cause-and-effect relationships, because this was a cross-sectional study. Our results may have been partially affected by data we were unable to collect, particularly those related to adherence to ARV therapy, and by the loss of information in some variables. However, this study has relevant points because it updates the genotypic data of an important region of Brazil with limited resources. In addition, we were able to establish the time 
in virologic failure and the ARV regimen before and after genotyping in the first virologic failure as well as the factors associated with the number of NRTI(t)-associated mutations and virologic success.

\section{Conclusions}

Patients in their first virologic failure who were seen at referral centers in the city of Recife, Pernambuco, Northeastern Brazil presented a high frequency of mutations pertaining to secondary resistance to the use of NRTI(t)s and NNRTIs. However, extensive resistance in reverse transcriptase did not impact the second-line virologic suppression after 48 weeks of the salvage therapy with $\mathrm{PI} / \mathrm{r}$ combined with active, partially active or inactive $\operatorname{NRTI}(t) s$. The time on ARVs to genotyping was an independent protective factor for a detectable viral load. Long-term follow-up is needed to support the use of partially active $\operatorname{NRTI}(t) s$ in salvage therapy regimens while controlling for adherence-related factors. Studies assessing the actual need for genotyping after the first virologic failure with NNRTIs are also needed.

\section{Abbreviations}

3TC: Lamivudine; ARVs: Antiretrovirals; ATV: Atazanavir; AZT: Zidovudine; CD4: CD4 T-cell counts; DRV/r: Darunavir/ritonavir; EFV: Efavirenz; GSS: Genotypic sensitivity score; IAS: International AIDS Society; LPV/r: Lopinavir/ritonavir; NNRTI: Non-nucleoside reverse transcriptase inhibitor; NRTI(t): Nucleos(t)ide reverse transcriptase inhibitor; NVP: Nevirapine; Pl: Protease inhibitors; PLHIV: People are living with HIV; SPSS: Statistical package for the social sciences; TAMs: Thymidine-associated mutations; TDF: Tenofovir; VL: Viral load

\section{Availability of data and materials}

The data that support the findings of this study are available from Federal University of Pernambuco but restrictions apply to the availability of these data, which were used under license for the current study, and so are not publicly available. Data are however available from the authors upon reasonable request and with permission of Federal University of Pernambuco.

\section{Authors' contributions}

All authors contributed equally. All authors read and approved the final manuscript.

\section{Ethics approval and consent to participate}

The study was submitted and approved by the ethics committee of Federal University of Pernambuco for the publication of this work. The informed consent was not obtained from all participants because it was waived by the ethics committee of Federal University of Pernambuco. Furthermore, the data was also de-identified. A copy of the written consent by ethics committee of Federal University of Pernambuco is available for review by the editor-in-chief of this journal. The authors declare that the procedures followed the regulations established by the local ethics committee of Federal University of Pernambuco and the helsinki declaration of the world medical association. Federal University of Pernambuco gave access to confidential patient medical records to the authors and these records were anonymous.

\section{Consent for publication}

Not applicable.

\section{Competing interests}

The authors declared no potential competing interest with respect to the research, authorship, and/or publication of this article.

\section{Publisher's Note}

Springer Nature remains neutral with regard to jurisdictional claims in published maps and institutional affiliations.

\section{Author details}

${ }^{1}$ Programa de Pós-graduação em Ciências da Saúde, Universidade Federal de Pernambuco, Av. Prof. Moraes Rego 1235, Recife 50670-901, Brazil. ${ }^{2}$ Instituto Aggeu Magalhaes, FIOCRUZ, Av. Prof. Moraes Rego 1235, Recife 50670-901, Brazil. ${ }^{3}$ Faculdade de Medicina do Recife, Universidade Federal de Pernambuco, Av. Prof. Moraes Rego, 1235, Recife, Pernambuco, Brazil.

Received: 28 February 2018 Accepted: 20 September 2018

Published online: 12 October 2018

\section{References}

1. 1 Joint United Nations Programme on HIV/AIDS. Global AIDS Update. 2016. http://www.unaids.org/en/topic/treatment. (Accessed Dec 20, 2017).

2. Strategies for Management of Antiretroviral Therapy (SMART) Study Group, El- Sadr WM, Lundgren J, Neaton JD, et al. CD4+ count-guided interruption of antiretroviral treatment. N Engl J Med. 2006;355:2283-96.

3. Rodger AJ, Cambiano V, Bruun T, et al. PARTNER study group. Sexual activity without condoms and risk of hiv transmission in serodifferent couples when the HIV- positive partner is using suppressive antiretroviral therapy. JAMA. 2016:316(2):171-81.

4. World Health Organization. HIV drug resistance report 2017. (https://www. who.int/hiv/pub/drugresistance/hivdr-report-2017/en/).

5. Campbell TB, Smeaton LM, Kumarasamy N, et al. Efficacy and safety of three antiretroviral regimens for initial treatment of HIV-1: a randomized clinical trial in diverse multinational settings. PLoS Med 2012; 9:e1001290. [sPubMed: 22936892].

6. Tilghman M, Tsai D, Buene TP, et al. Pooled nucleic acid testing to detect antiretroviral treatment failure in HIV-infected patients in Mozambique. J Acquir Immune Defic Syndr. 2015;70:256-261. [PubMed: 26135327].

7. Joint United Nations Programme on HIV/AIDS. Global AIDS Update. 2016. In: Accessed 20 Dec 2017.

8. Brasil. Protocolo Clínico e Diretrizes Terapêuticas para Manejo da Infecção pelo HIV em Adultos. Data de publicação: 03/10/2013. Data última atualização: 31/07/2015. Available at https://www.aids.gov.br/tags/ publicacoes/protocolo-clinico-e-diretrizes-terapeuticas. (Accessed 20 Aug 2017).

9. Brasil. Protocolo Clínico e Diretrizes Terapêuticas para Manejo da Infecção pelo HIVem Adultos. Data de publicação: 2017. Available at www.aids.gov. br/tags/publicacoes/protocolo-clinico-e-diretrizes-terapeuticas. (Accessed 01 Dec 2017).

10. Matsuda EM, Coelho LP, Romero G, et al. High prevalence of drug resistance mutations among patients failing first-line antiretroviral therapy and predictors of virological response 24 weeks after switch to second-line therapy in São Paulo state, Brazil. AIDS Res Hum Retroviruses. 2017;34(2):127. http://doi.org/10.1089/aid.2017.0052.

11. Brites $C$, Pinto-Neto L, Medeiros $M$, et al. Extensive variation in drugresistance mutational profile of Brazilian patients failing antiretroviral therapy in five large Brazilian cities. Braz J Infect Dis. 2016;20(4):323-9.

12. World Health Organization. Consolidated Guidelines on the use of antiretroviral drugs for treating and preventing HIV infection. https://www.who.int/hiv/ pub/arv/treatment-monitoring-info-2017/en/ (Accessed 20 Dec 2017).

13. Boyd MA, Kumarasamy N, Moore $\mathrm{CL}$, et al. for the second-line study group. Ritonavir-boosted lopinavir plus nucleoside or nucleotide reverse transcriptase inhibitors versus ritonavir-boosted lopinavir plus raltegravir for treatment of HIV-1 infection in adults with virological failure of a standard first-line ART regimen (SECOND-LINE): a randomised, open-label, noninferiority study. Lancet. 2013;381:2091-9.

14. Paton NI, Kityo C, Hoppe A, et al. EARNEST trial team. Assessment of second- line antiretroviral regimens for HIV therapy in Africa. N Engl J Med. 2014;371(3):234-47.

15. La Rosa AM, Harrison LJ, Taiwo B, et al. Raltegravir in second-line antiretroviral therapy in resource-limited settings (SELECT): a randomised, phase 3, non- inferiority study. Lancet HIV. 2016;3:e247-58.

16. 2017 Resistance Mutations Update. Volume 24, Issue 4, Dec. 2016/January 2017. Available at https://www.iasusa.org/sites/default/files/uploads/2017hivmuta-article.pdf. Accessed in 01/20/2017. 
17. Cavalcanti AM, Lacerda HR, Brito AM, et al. Antiretroviral resistance in individuals presenting therapeutic failure and subtypes of the human immunodeficiency virus type 1 in the northeast region of Brazil. Mem Inst Oswaldo Cruz. 2007:102:785-92.

18. Lacerda HR, Medeiros LB, Cavalcanti AM, et al. Comparison of the epidemiology, profile of mutations, and clinical response to antiretrovirals among subtypes B and $F$ of the human immunodeficiency virus type 1. Mem Inst Oswaldo Cruz. 2007;102:693-9.

19. Lima K, de Souza Leal É, AMS C, Salustiano DM, de Medeiros LB, da Silva SP, et al. Epidemiological, Clinical and Antiretroviral Susceptibility Characterization of Human Immunodeficiency Virus Subtypes B and Non-B in Pernambuco, Northeast Brazil. PLoS One. 2016;11(5):e0155854.

20. Kanters S, Socias ME, Paton NI, et al. Comparative efficacy and safety of second- line antiretroviral therapy for treatment of HIV/AIDS: a systematic review and network meta-analysis. The Lancet HIV. 2017;3018(17):1-9.

21. Gräf T, Vrancken B, Maletich Junqueira D, et al. Contribution of epidemiological predictors in unraveling the phylogeographic history of HIV-1 subtype C in Brazil. J Virol. 2015;89:12341-8.

22. Velasco-de-Castro CA, Grinsztejn B, Veloso VG, et al. HIV-1 diversity and drug resistance mutations among people seeking HIV diagnosis in voluntary counseling and testing sites in Rio de Janeiro, Brazil. PLoS One. 2014;9(1):e87622.

23. Miller MD, Margot N, Lu B, Zhong L, et al. Genotypic and phenotypic predictors of the magnitude of response to tenofovir disoproxil fumarate treatment in antiretroviral- experienced patients. J Infect Dis. 2004;189(5):837-46.

24. Melikian GL, Rhee SY, Taylor J, et al. Standardized comparison of the relative impacts of HIV-1 reverse transcriptase (RT) mutations on nucleoside RT inhibitor susceptibility. Antimicrob Agents Chemother. 2012;56(5):2305-13.

25. Lopes CA, Soares MA, Falci DR, Sprinz E. The evolving genotypic profile of HIV- 1 mutations related to antiretroviral treatment in the north region of Brazil. Biomed Res Int. 2015;2015:738528e.

26. Hamers RL, Sigaloff KC, Wensing AM, et al. PharmAccess African studies to evaluate resistance (PASER). Patterns of HIV-1 drug resistance after first-line antiretroviral therapy (ART) failure in 6 sub-Saharan African countries: implications for second-line ART strategies. Clin Infect Dis. 2012;54(11):1660-9.

27. Sivamalar S, Dinesha TR, Gomathi S, et al. Accumulation of HIV-1 drug resistance mutations after first-line immunological failure to evaluate the options of recycling NRTI drugs in second-line treatment: a study from South India. AIDS Res Hum Retrovir. 2017;33(3):271-4.

28. The TenoRes Study Group. Global epidemiology of drug resistance after failure of WHO recommended fi rst-line regimens for adult HIV-1 infection: a multicentre retrospective cohort study. Lancet Infect Dis. 2016;16:565-75.

29. Ford N, Shubber Z, Hill A, et al. Comparative efficacy of lamivudine and Emtricitabine: a systematic review and meta-analysis of randomized trials. PLoS One. 2013;8(11):e79981.

30. Von Wyl V, Yerly S, Böni J, et al. Swiss HIV cohort study. Incidence of HIV-1 drug resistance among antiretroviral treatment-naive individuals starting modern therapy combinations. Clin Infect Dis. 2012;54(1):131-40.

31. Van Zyl GU, Liu TF, Claassen M, Engelbrecht S, et al. Trends in genotypic HIV-1 antiretroviral resistance between 2006 and 2012 in south African patients receiving first and second-line antiretroviral treatment regimens. PLoS One. 2013;8(6):e67188.

32. Stevens WS, Wallis CL, Sanne I, Venter F. Will etravirine work in patients failing nonnucleoside reverse transcriptase inhibitor-based treatment in southern Africa? J Acquir Immune Defic Syndr. 2009;52(5):655-6.

33. Kiertiburanakul S, Wiboonchutikul S, Sukasem C, Chantratita W, Sungkanu- parph S. Using of nevirapine is associated with intermediate and reduced response to etravirine among HIV-infected patients who experienced virologic failure in a resource- limited setting. J Clin Virol. 2010;47(4):330-4.

34. Taiwo B, Chaplin B, Penugonda S, et al. Suboptimal Etravirine activity is common during failure of Nevirapine-based combination antiretroviral therapy in a cohort infected with non-B subtype HIV-1. Curr HIV Res. 2010;8(3):194-8.

35. Paton, N, Kityo, C, Thompson, J, et al. Impact of NRTI cross-resistance on second-line PI + NRTI therapy outcomes in Africa; Conference on Retrovirus and Opportunistic Infections; Seattle, WA, USA. Feb 23-26, 2015;119 (abstr).
36. Lam EP, Moore CL, Gotuzzo E, et al. Antiretroviral resistance ater first-line anti- retroviral therapy failure in diverse HIV-1 subtypes in the SECOND-LINE study. AIDS Res Hum Retrovir. 2016;32:841-50.

37. Cozzi-Lepri A, Phillips AN, Martinez-Picado J, et al. EuroSIDA study group. Rate of accumulation of thymidine analogue mutations in patients continuing to receive virologically failing regimens containing zidovudine or stavudine: implications for antiretroviral therapy programs in resourcelimited settings. J Infect Dis. 2009;200(5):687-97.

38. Molina JM, Cohen C, Katlama C, Grinsztejn B, Timerman A, Pedro RD. et al. Safety and efficacy of darunavir (TMC114) with low-dose ritonavir in treatment- experienced patients: 24-week results of POWER 3. J Acquir Immune Defic Syndr. 2007:46:24-31.

39. Grinsztejn B, Nguyen B-Y, Katlama C, et al. For the Protocol 005Team. Safety and efficacy of the HIV-1 integrase inhibitor raltegravir (MK-0518) in treatment- experienced patients with multidrug-resistant virus: a phase II randomised controlled trial. Lancet. 2007;369:1261-9.

40. Duani H, Aleixo AW, Tupinambás U. Trends and predictors of HIV-1 acquired drug resistance in Minas Gerais, Brazil: 2002-2012. Braz J Infect Dis. 2017;21(2):148-54.

41. Nucleoside reverse-transcriptase inhibitor cross-resistance and outcomes from second-line antiretroviral therapy in the public health approach: an observational analysis within the randomised, open-label, EARNEST trial.

42. Horizons/Population Council, International Centre for Reproductive Health and Coast Province General Hospital, Mombasa-Kenya. Adherence to Antiretroviral Therapy in Adults: A Guide for Trainers. Nairobi: Population Council. 2004. Available from: http://www.popcouncil.org/uploads/pdfs/ horizons/mombasaarvtrainingguide.pdf. Accessed 6 Feb 2018.

43. Shigdel R, Klouman E, Bhandari A, et al. Factors associated with adherence to antiretroviral therapy in HIV-infected patients in Kathmandu District, Nepal. HIV AIDS (Auckl). 2014;6:109-16.

44. Vandenhende MA, Ingle S, May M, et al. Impact of low-level viremia on clinical and virological outcomes in treated HIV-1-infected patients: the antiretroviral therapy cohort collaboration (ART-CC). AIDS. 2015;29(3):373-83.

\section{Ready to submit your research? Choose BMC and benefit from:}

- fast, convenient online submission

- thorough peer review by experienced researchers in your field

- rapid publication on acceptance

- support for research data, including large and complex data types

- gold Open Access which fosters wider collaboration and increased citations

- maximum visibility for your research: over $100 \mathrm{M}$ website views per year

At BMC, research is always in progress.

Learn more biomedcentral.com/submissions 